\title{
Novos atores no mercado: movimentos sociais econômicos e consumidores politizados
}

Fátima Portilho*

\section{Resumo}

$\mathrm{O}$ artigo reflete sobre os novos atores do mercado, em especial os movimentos sociais econômicos, ou seja, aqueles em que os atores constroem uma nova cultura de ação política visando a reapropriação da economia a partir de valores próprios. Exemplo disso são os movimentos de economia solidária, comércio justo, indicação geográfica, slow food e os movimentos de consumidores organizados. Esta interface entre movimentos sociais e mercado é, talvez, a característica mais marcante, diferenciadora e polêmica das mobilizações políticas atuais. No entanto, para além dos movimentos sociais econômicos, o artigo enfatiza e, ao mesmo tempo, problematiza a ação política na esfera do consumo individual, o que tem sido chamado de consumo político.

Palavras-chave: movimentos sociais econômicos, movimentos de consumidores, consumo político.

\section{Introdução: Sociologia Econômica e Sociologia do Consumo: interfaces necessárias}

\begin{abstract}
o buscar uma necessária interface entre as reflexões da Sociologia Econômica e da Sociologia do Consumo, poderíamos destacar o empenho de ambas em (a) fornecer explicações alternativas às teorias econômicas, em especial à teoria neoclássica, e em (b) refletir sobre a atuação dos novos movimentos sociais econômicos, ou seja, aque-
\end{abstract}

* Doutora em Ciências Sociais. Professora do CPDA da Universidade Federal Rural do Rio de Janeiro. Grupo de Pesquisa Sociedades e Culturas de Consumo. Núcleo de Pesquisa Mercados, Redes e Valores. Endereço eletrônico: faportilho@uol.com.br. 
les em que os atores constroem uma nova cultura de ação política visando à reapropriação do mercado a partir de valores próprios.

Como exemplo dos novos movimentos sociais econômicos podemos citar, de um lado, movimentos como economia solidária, comércio justo, indicação geográfica e slow food, que tem sido considerados como novos atores estratégicos do mercado (WIKINSON, 2008). Além destes, vale destacar também os movimentos de consumidores organizados.

Se os primeiros têm sido objeto de pesquisas nas Ciências Sociais, especialmente na Sociologia Econômica, os movimentos de consumidores, no entanto, raramente são abordados no Brasil ${ }^{1}$, permanecendo ausentes até mesmo nos estudos sobre movimentos sociais, área tradicional de investigação nas Ciências Sociais brasileiras e latino-americanas ${ }^{2}$.

Essa ausência de análises acadêmicas sobre os movimentos de consumidores no Brasil ${ }^{3}$ reflete uma outra ausência, mais ampla, de análises sobre o fenômeno do consumo contemporâneo, o que contrasta com a ênfase dada a este tema por autores da Europa e dos Estados Unidos (MILLER, 1995 e 2001), onde se observa vasta produção acadêmica abordando temas como a sociedade de consumo, as novas formas de comercialização, a cultura material, as práticas de consumo e seus usos sociais, entre outros (BARBOSA, 2006).

Isto pode ser explicado, de um lado, pelo viés produtivista das Ciências Sociais que, desde o século XIX, baseou-se no pressuposto

1 As publicações voltadas para esse tema no Brasil costumam se restringir às áreas de direito, administração e marketing como, por exemplo, os trabalhos de Vergara (2003) e Sodré (2009).

2 As razões dessa ausência podem estar no fato de que os movimentos de consumidores não têm caráter revolucionário, mas antes de modernização do capitalismo, buscando, de acordo com seus militantes, a "compatibilização entre os interesses dos consumidores e dos fornecedores" (RIOS, LAZZARINI \& NUNES JR. 2001). Considerando os limites e os propósitos desse artigo, não será possível aprofundar a reflexão sobre atuação e as contradições dos movimentos de consumidores.

3 Vale destacar a análise de Freitas (2008), ainda em andamento, sobre a atuação dos movimentos de consumidores, juntamente com movimentos ambientalistas, nas mobilizações sociais contrárias aos alimentos transgênicos. Em trabalho anterior (PORTILHO, 2006) analisamos, ainda que parcialmente, o processo de ambientalização dos movimentos de consumidores. 
de que a compreensão das modernas sociedades capitalistas se daria a partir do complexo institucional necessário à produção de riquezas. Somando-se ao viés produtivista, um viés de cunho moralista e moralizante das Ciências Sociais também nos ajuda a explicar essa ausência, pois trabalho e produção sempre foram considerados moralmente superiores ao consumo, fazendo com que a crítica e o julgamento moral das práticas de consumo acabasse se sobressaindo à análise sociológica deste fenômeno. A partir da década de 80 do século XX, no entanto, o campo do consumo passou a ser visto como um fenômeno central em todas as sociedades e fundamental para compreender as transformações do final do século XX e início do XXI (BARBOSA \& CAMPBELL, 2006).

Mas o que designamos, genericamente, por movimento de consumidores parece representar, pelo menos, três categorias distintas de movimento social, com objetivos e ações, às vezes, bem diferentes entre si: (a) os movimentos de defesa dos direitos dos consumidores, ou consumerismo, que surge como reação à situação de desigualdade entre fornecedores e consumidores, construindo a noção de direito do consumidor; (b) os movimentos anticonsumo, vinculados à crítica à "sociedade de consumo" e (c) os movimentos pró-consumo responsável, que visam a construir uma nova cultura de ação política através das práticas de consumo (PORTILHO, 2006).

No entanto, para além dos novos movimentos sociais econômicos e, entre eles, os movimentos de consumidores, pretendo enfatizar aqui formas de participação e ação política na esfera do consumo individual, o que tem sido chamado de consumo político. Trata-se, conforme veremos, de uma ação política inovadora e não institucionalizada que, ao contrário da privatização da política, pode ser analisada como politização da vida privada, ampliando o espaço da política.

Para isso, porém, torna-se necessário debruçar-nos um pouco sobre o fenômeno do consumo, indo além das abordagens economicistas - que enfatizam a teoria da escolha racional e independente e a teoria da demanda, baseada no indivíduo isolado e autocentrado - e das abordagens marxistas, frankfurtianas e pós-modernas - que tendem a minimizar as complexas variações individuais e grupais presentes nas práticas de consumo (EDWARDS, 2000; PAAVOLA, 
2001; DOUGLAS \& ISHERWOOD, 2006; BARBOSA \& CAMPBELL, 2006; MILLER, 1995 e 2001; HARVEY et al., 2001).

A Sociologia e a Antropologia do Consumo, ao contrário, têm buscado avançar no argumento de que os bens de consumo (códigos compartilhados e, portanto, compreensíveis) funcionam tanto como reprodução física e biológica quanto como reprodução social e mediação de relações sociais.

Questionando a validade de um olhar universalizante, Douglas \& Isherwood (2006) mostram que as atividades de consumo têm origens culturais, mais do que econômicas, e, portanto, não podem ser explicadas pela racionalidade do comportamento econômico ${ }^{4}$.

Assim, mais do que reprodução das estruturas sociais reinantes (BOURDIEU, 2008), busca por status ou, ainda, resultado e objetivo do trabalho ${ }^{5}$, consumo é compreendido como um processo social produtor de significados e identidades que nos ajudam a ordenar o mundo a nossa volta, tornando-o compreensível (DOUGLAS \& ISHERWOOD, 2006).

Nesta abordagem, os bens de consumo são usados para estabelecer, manter e marcar relações sociais. O consumo é, portanto, sempre relacional, e os bens são acessórios ritualísticos, ou seja, são utilizados em rituais e eventos sociais para marcar fronteiras e hierarquias, construindo barreiras ou pontes entre pessoas e entre grupos de pessoas. Assim, o objetivo principal de um consumidor é construir um universo inteligível com as mercadorias que seleciona. Os bens de consumo servem para marcar periodizações e intervalos

4 Para os autores, a idéia de consumidores individuais buscando a maximização do seu bem-estar é uma abstração, impossível na vida social, baseada em idéias implícitas e não em dados empíricos: "é claramente absurdo agregar milhões de indivíduos que compram e usam bens sem considerar as transformações que provocam ao compartilharem o consumo" (p.27).

5 Questionando a separação entre prazer e trabalho proposta pela teoria utilitarista, Douglas \& Isherwood (2006) mostram que as abordagens que tratam o consumo como resultado e objetivo do trabalho acabam negando a importância do trabalho em si mesmo, "tratando-o sempre como insumo de alguma outra coisa" (p.59), sem considerar que a atividade econômica pode ser vivida como auto-expressão e realização criativa. Nesse sentido, os autores propõem restaurar o sistema produção/consumo, considerando-o um processo circular, e não uma via de mão única, dos fatores de produção aos bens de consumo. 
entre as obrigações sociais, sendo, portanto, a parte visível de uma cultura. Em vez de supormos que são, em primeiro lugar, necessários à exibição pública competitiva, devemos supor que sejam necessários para dar visibilidade e estabilidade às categorias da cultura, já que as escolhas e posses materiais, como é amplamente demonstrado por pesquisas etnográficas, carregam significação social. Isso nos leva a considerar o consumo como comunicadores, materializando valores e visões de mundo de seus usuários (idem).

Além disso, as escolhas de consumo estão sempre enraizadas em experiências concretas de pertencimento a uma determinada comunidade moral - no sentido antropológico, ou seja, um grupo de indivíduos que partilham a mesma base normativa - onde algumas escolhas são consideradas moralmente corretas e superiores a outras. O consumo, dessa forma, é definido como uma área de comportamento cercada por regras e valores morais. Decisões como o que comprar, quanto gastar e quanto economizar são, portanto, decisões morais que expressam e produzem cultura.

No entanto, a incorporação de valores como solidariedade, ética e responsabilidade nos discursos, escolhas e práticas de consumo, conforme proposto por alguns movimentos sociais, exige de sociólogos e antropólogos uma revisão no próprio conceito de sociedade e cultura de consumo, pois, ao incorporar tais valores, tais práticas têm sido usadas, também, como uma forma inovadora de ação política e participação na esfera pública.

Em um contexto de sociedades globais de risco, destradicionalizadas e de alta reflexividade social, o desafio de compatibilizar o micro e o macro, o local e o global, a esfera privada e a pública traz o campo do consumo para uma posição mais central, tanto nas práticas políticas quanto nos debates e pesquisas acadêmicas.

O objetivo central deste artigo é, portanto e centralmente, refletir sobre consumidores difusamente politizados enquanto atores do mercado. Em especial, interessa indagar se conjugam ou não a participação via consumo com formas institucionalizadas e coletivas de participação.

A segunda parte do artigo aborda os novos movimentos sociais econômicos, enfatizando os movimentos de consumidores organiza- 
dos. A terceira parte, por sua vez, reflete e, ao mesmo tempo, problematiza o consumo político, ou seja, a percepção e o uso do consumo como forma de ação política. Como conclusão, apresentamos uma necessária agenda de pesquisa, levantando algumas questões que merecem reflexões futuras e análise de dados empíricos ${ }^{6}$.

\section{Novos atores no mercado: movimentos sociais econômicos}

Em um contexto de grandes transformações - incluindo a desregulamentação e a globalização dos mercados, a transnacionalização dos atores sociais e a centralidade do consumo - diversos movimentos sociais têm alterado seu foco, suas demandas e suas estratégias, buscando formas inovadoras de ação política, com destaque para o uso de mecanismos econômicos para cumprir objetivos sociais.

O mercado, mais do que o Estado, passa a ser o objetivo central e espaço de atuação dos chamados novos movimentos sociais econômicos (GENDRON et ali, 2006), ou seja, aqueles em que os atores constroem uma nova cultura de ação política visando a reapropriação da economia a partir de valores próprios. Esta interface entre movimentos sociais e mercado é, talvez, a característica mais marcante, diferenciadora e polêmica das mobilizações políticas atuais.

No entanto, embora estes movimentos abordem problemáticas econômicas e de redistribuição, o fazem a partir de propostas de mudanças culturais e de demandas por reconhecimento (idem). Voltam-se para o questionamento das assimetrias do comércio mundial e para a construção de propostas alternativas e mais autônomas de comércio, visando a reduzir as desigualdades das trocas comerciais entre produtores dos países do Sul e consumidores dos países

6 Está em andamento o desenho de um projeto de pesquisa sobre consumo político no Brasil, a exemplo de pesquisa realizada em paises europeus (STOLLE et ali, 2005), a ser desenvolvido a partir de parceria entre pesquisadores do Grupo de Pesquisa Sociedades e Culturas de Consumo e a pesquisadora Michele Micheletti, da Universidade Karlstad/Suécia. 
do Norte. Assim, organizam redes alternativas de comercialização, enfatizam diferentes formas de rotulagem de produtos (comercializados tanto em redes alternativas quanto em redes varejistas convencionais) promovem campanhas visando a ação via práticas de compras e propõem novas regras para o comércio convencional (WILKINSON, 2007 e 2008).

As análises de Wilkinson (2002, 2007 e 2008) têm apontado para um processo de endogeneização da crítica ética e estética, através do qual mercado e movimentos sociais se retroalimentam por meio de uma "dialética sem síntese".

Orientados ao mercado (market oriented movements), movimentos sociais econômicos buscam redefinir as relações produtorconsumidor e, portanto, dependem crucialmente da politização do consumo, tanto na esfera doméstica convencional quanto na esfera institucional, em que Estado, empresas, ONGs e outras organizações passam a ser consideradas consumidores, dentro do enfoque do consumo organizacional (GREEN, MORTON \& NEW, 2000; DOUGLAS \& ISHERWOOD, 2006; WILKINSON, 2008).

Economia Solidária, Comércio Justo, Produtos Orgânicos, Indicação geográfica e Slow Food têm sido apontados como exemplos de movimentos sociais econômicos que, embora correndo os riscos da cooptação e de excluir pequenos produtores, buscam redefinir o mercado e os valores em jogo (WILKINSON, 2008). Neste conceito, podemos incluir, ainda, os movimentos de consumidores, pouco estudados pela Sociologia Econômica, pela Sociologia do Consumo e, menos ainda, pela Sociologia dos Movimentos Sociais.

Em uma primeira aproximação analítica, os movimentos de consumidores parecem distinguir-se em, pelo menos, três categorias distintas: os movimentos de defesa dos direitos dos consumidores, os movimentos anti-consumo e os movimentos pró-consumo responsável.

Os movimentos de defesa dos direitos dos consumidores, denominados de consumerismo, em tradução do termo inglês consumerism, surgiram na esteira dos movimentos de construção dos "novos direitos". Entendidos como um movimento social organizado próprio da Sociedade de Consumo, surgem como reação à 
situação de desigualdade e assimetria de poder e informação entre fornecedores e consumidores. Trata-se de um movimento que luta por direitos que vão além da defesa da soberania do consumidor, buscando, ao contrário, reverter a influência do mercado. $\mathrm{O}$ consumerismo atua, principalmente, na esfera jurídica, considerando os direitos dos consumidores como direitos dos cidadãos em suas relações com o mercado (RIOS, LAZZARINI \& NUNES JR., 2001). Além disso, atua também como "conselheiro dos consumidores", fazendo e divulgando testes comparativos de produtos para oferecer ao consumidor a melhor opção de compra. Temática bastante explorada nas Ciências Sociais dos países europeus e, principalmente, dos EUA, o tema ainda é pouco investigado no Brasil.

No âmbito internacional, destaca-se a Consumers International, federação internacional de organizações de consumidores, com mais de 200 organizações filiadas, de mais de 80 países, que se dedica à proteção e promoção dos direitos dos consumidores perante organismos regionais e internacionais. No âmbito nacional merece destaque a atuação do IDEC (Instituto Brasileiro de Defesa do Consumidor) e a criação, em 1997, do Fórum Nacional das Entidades Civis de Defesa dos Direitos dos Consumidores (FNECDC), instância de articulação das organizações sociais que atuam na defesa do consumidor, contando com a participação de 21 entidades de 13 estados brasileiros.

Os movimentos anticonsumo, por sua vez, nasceram junto com a própria sociedade de consumo (EDWARDS, 2000; BAUDRILLARD, 1995). Polêmica de mais de dois mil anos, o discurso contra o luxo, a opulência, o desperdício, o hedonismo e a desmedida tem sido sempre renovado por diferentes argumentos, tanto morais quanto religiosos, éticos, políticos e econômicos. Alguns exemplos clássicos são a "utopia da suficiência", de Thomas More (1516), a "utopia da simplicidade", de Henry Thoreau (1854) e a "utopia da beleza austera”, de Wiliam Morris (1888) (GEUS, 1999). Com o chamado Novo Ambientalismo ${ }^{7}$ surgem novos argumentos contra os hábitos

7 O termo Novo Ambientalismo é utilizado por McCormick (1992) para denominar o movimento de massas que surgiu nos EUA, na década de 70 do século XX e que, ao contrário do ambientalismo do período anterior (restrito a cientistas, administradores e grupos conservacionistas), se caracteriza pelo ativismo político. 
considerados consumistas, como as utopias "Small is beautiful", de Fritz Shumacher (1974), da "frugalidade", de William Ophuls (1977), da "sociedade ecológica", de Murray Bookchin (1980) e do "abandono da afluência”, de Ted Trainer (1985) (DOBSON, 1991).

Assim, se tais movimentos e utopias tradicionalmente enfatizavam a crítica social e moral ao "consumismo", foram atualizados pelos movimentos ambientalistas e sua crítica aos impactos ambientais dos padrões e níveis de consumo das sociedades contemporâneas. Poderíamos pensá-los, portanto, como uma espécie de releitura e atualização dos movimentos anteriores, acrescentando novas questões trazidas pela globalização, pelos movimentos ambientalistas, pelo desenvolvimento das novas tecnologias da informação, pela biotecnologia e pelo advento da chamada Sociedade de Risco. Nesse sentido, podemos considerá-los a partir da perspectiva pós-materialista ${ }^{8}$ e como um "novo movimento anticonsumo" (PORTILHO, 2005), ou seja, um conjunto de debates e proposições que, apesar da semelhança com aqueles liderados pelos movimentos contraculturais da década de 60, se estabeleceu sob bases teóricas e ideológicas diferentes (ZAVESTOSKI, 2001). Tais movimentos se fortalecem na esteira dos movimentos anticapitalismo e antiglobalização. Dentre suas estratégias de ação, podemos citar eventos como o "Dia de não comprar nada" e o "Dia sem carro".

Organizações de várias partes do mundo têm se voltado para questões como estas, dentre elas as ONGs internacionais Adbuster e AntiPub. Vale citar, ainda, movimentos como "simplicidade voluntária”, detalhado por Duane Elgin (ELGIN, 1993), "círculos de simplicidade", por Cecile Andrews (ANDREWS, 1997), e o movimento "sem logo", proposto por Naomi Klein (KLEIN, 2000). Tais movimentos enfatizam uma crítica às "Sociedades de Consumo" e à fraca relação entre consumo e felicidade ou realização humana. A americana Juliet B. Schor, por exemplo, ganhou notoriedade com a publicação dos livros The overworked American, The overspent American e The

8 A teoria do pós-materialismo, desenvolvida por Robert Inglehart, no final da década de 70 , defende que o rápido crescimento econômico a partir da Segunda Guerra Mundial levou à satisfação das necessidades materiais para a vasta maioria da população do Ocidente, tornando possível a busca por valores pós-materialistas, tais como apreciar a natureza. 
cycle of work and spend, que denunciam o estilo de vida baseado no círculo vicioso de "excesso de trabalho para alimentar um excesso de consumo ostentatório que não traz felicidade" (SCHOR, 1998). No âmbito brasileiro, podemos citar o Instituto Alana e o Fórum Criança e Consumo.

Finalmente, os movimentos pró-consumo responsável surgem na esteira dos movimentos de ampliação da cidadania, percebendo os consumidores, não como vítimas, mas como importantes e decisivos atores do mercado e enfatizando a auto-atribuição de responsabilidades por parte dos consumidores individuais (PORTILHO, 2008).

Ao contrário do que possa parecer, estas estratégias de uso político do consumo não são novas. Autores como Blee (1985), Frank (1991 e 1994), Linden (1994), Cohen (2001), Ferreras (2001) e Stolle et ali (2005) analisam exemplos históricos que indicam a percepção da exploração no consumo seguida de protestos dos consumidores, desde o século XVII, relacionadas em geral ao aumento de preços e à estrutura de produção e distribuição. Outros exemplos apontam que a luta de operários muitas vezes extrapolou as tradicionais ações no local de trabalho para ações de politização do consumo.

Linden (1994) enfatiza a forma de poder resultante do uso coletivo do poder de compra das classes trabalhadoras. Blee (1985) ressalta diversos exemplos, desde o século XVII, em que revoltas de consumidores precederam outras formas de protesto. Frank (1991 e 1994) aborda a mudança de tática do movimento operário de Seattle/ EUA e suas famílias que organizaram, entre 1919 e 1929, diversas atividades no sentido de fortalecer seu poder enquanto consumidores, pressionando seus empregadores não apenas nos locais de trabalho, mas também nos locais de consumo (o boicote à loja de departamentos Bon Marché, a criação de cooperativas de consumo como alternativa de compras e a "rotulagem sindical"). Ferreras (2006) analisa uma estratégia semelhante utilizada pelo movimento operário de Buenos Aires, no período entre 1880 e 1920. Stolle et ali (2005) citam diversos outros exemplos de uso de boicotes como tática de pressão política, sendo o mais conhecido o boicote empreendido por afro-americanos contra o sistema de ônibus da cidade Montgomery (Alabama/EUA), nos anos 50, como parte do movimento 
de luta pela ampliação dos direitos civis e contra a segregação racial. No Brasil os estudos historiográficos e sociológicos sobre boicotes são ainda raros e periféricos, com destaque para a obra de Edson Nunes sobre a Revolta das Barcas, ocorrida nas cidades de Niterói e Rio de Janeiro/RJ, em 1959 (NUNES, 2000).

Como exemplo de movimento pró-consumo responsável destaca-se, no âmbito internacional, a ONG Ethical Consumer e, no brasileiro, as ONGs ICONES (Instituto para o Consumo Educativo Sustentável do Pará), Faces do Brasil, Instituto Kairós e, numa perspectiva um pouco diferente, o Instituto Akatu para o Consumo Consciente.

Tais instituições, em geral, apontam para a importância de se construir uma espécie de "agenda da mesa da cozinha" (HALKIER, 1999) e formas inovadoras de ação política, como "votar com a carteira" (DOBSON, 1991) e "votar com o garfo" (NESTLE, 2002), numa alusão à "invasão" da política na esfera cotidiana.

A consideração destes movimentos, ainda escassa entre os cientistas sociais brasileiros, leva-nos a concordar com a idéia de que a "soberania do consumidor" pode estar movendo-se em direção à "cidadania do consumidor", em que os indivíduos constituem o consumo como uma ativa prática social, política e ecológica" (ISIN \& WOOD, 1999, p.158).

\section{Novos atores no mercado: consumidores difusamente politizados}

Para além dos movimentos de consumidores organizados, surge a necessidade de refletir e compreender o crescente uso do consumo individual como uma forma de ação política que incorpora, de diferentes maneiras e diferentes graus, preocupações e valores em prol do meio ambiente e da justiça social. Questões relacionadas a esta temática têm sido discutidas por autores como Canclini (1996), Halkier (1999), Stolle et ali (2005), Micheletti (2003) e Portilho (2005 e 2008), que percebem o consumo como forma de materializar valores e torná-los públicos.

Esta forma de abordagem, ao contrário de considerar os consumidores como indivíduos alienados, manipulados, fragmentados 
e auto-interessados, os percebe como sujeitos ativos. Ao mesmo tempo, esta abordagem evita associar consumo, automaticamente, a noções como consumismo, materialismo, individualismo, hedonismo, luxo e consumo conspícuo. Ao contrário, consumo é entendido como atividade cotidiana e rotineira de abastecimento do lar com bens necessários à reprodução material e simbólica. No processo de seleção de mercadorias, os consumidores desenvolvem e imaginam as relações sociais e os valores que mais lhes importam, fazendo com que o ato de compra se transforme "num meio de conferir objetividade a certos valores" (MILLER, 2002, p.79).

Vale frisar que o enfoque do consumo político não aborda consumidores engajados em movimentos sociais institucionalizados, tais como os movimentos de defesa dos direitos dos consumidores, movimentos anti-consumo ou movimentos pró-consumo responsável, acima citados. Ao contrário, esta abordagem enfatiza justamente aqueles atores sociais "não-organizados" e difusamente politizados 9 que se situam entre o anonimato e a vontade de exercer um papel político, entre as preocupações cotidianas da esfera privada e a vontade de participar de uma esfera pública mais ampla (PAAVOLA, 2001; PORTILHO, 2005).

Nesse sentido, alguns estudos (CANCLINI, 1996; GIDDENS, 1996; BECK, 2002; MICHELETTI, 2003; PORTILHO, 2005; STOLLE et ali, 2005) apontam para uma possível mudança das formas convencionais de participação política (sindicatos, partidos, eleições e movimentos sociais institucionalizados) para formas consideradas mais autônomas, menos hierárquicas e não institucionalizadas de participação, tais como boicotes, compras responsáveis (buycotts ${ }^{10}$ ) e o uso consciente de recursos naturais na esfera doméstica (água, energia, automóvel, separação de lixo etc.).

9 Devo esta expressão a John Wilkinson, a quem agradeço as valiosas contribuições a esta reflexão.

10 O neologismo buycott tem sido utilizado na língua inglesa como contraponto à expressão boycott. Enquanto este último refere-se à negação da compra por motivos políticos, éticos, ideológicos ou ambientais, uma ação de buycott refere-se à opção consciente de compra de produtos e serviços percebidos como social e ambientalmente responsáveis. 
Assim, ao contrário das abordagens que consideram os consumidores como vítimas passivas, esta abordagem analisa processos sociais concretos em que muitos consumidores se auto-atribuem responsabilidades e deveres com relação a problemas sociais e ambientais (EDEN, 1993; SCHWARTZ, 1998; PORTILHO, 2008).

O fenômeno do consumo político é considerado como uma encruzilhada de valores e práticas em disputa (consumption junction, na expressão de STOLLE et ali, 2005), onde ocorrem processos de negociação e incorporação dos ideais de solidariedade e sustentabilidade nas atividades da vida diária dos cidadãos (HALKIER, 1999; MICHELETTI, 2003). Tensões, dilemas, incorporação, negociação e negação destes ideais, no entanto, precisam ser mais bem examinados a partir de pesquisas empíricas que analisem como, de que forma e porque (ou porque não) os cidadãos individuais percebem suas responsabilidades e seu papel.

Afinal, se a cultura do consumo tornou-se mais proeminente, aumentaram os espaços e as formas de ação política e participação através de práticas de consumo percebidas como emancipatórias e reflexivas, expressando e fortalecendo uma nova cultura política, através de formas criativas e inovadoras de participação (CANCLINI, 1996; HALKIER, 1999; MICHELETTI, 2003; PORTILHO, 2005). Ao mesmo tempo, o consumo de massa perdeu espaço para formas de consumo especializado, dando espaço para uma economia de qualidades e singularidades (LASH \& URRY, 1994; WILKINSON, 2006). Tudo isso, parece ter levado ao que se convencionou chamar de ambientalização e politização da vida privada, abrindo espaço para um maior protagonismo dos consumidores.

Mas como explicar o fenômeno do consumo político nas sociedades contemporâneas? Alguns autores e teorias podem ser mobilizados para nos ajudar a compreender o crescimento da participação política via escolhas e práticas de consumo. Apresentamos abaixo algumas pistas teóricas ${ }^{11}$.

11 Tais pistas teóricas foram abordadas com mais detalhes em Portilho \& Castañeda (2009). 
Em termos teóricos, estas práticas políticas renovadas e que ocupam novos espaços fora do campo político tradicional, podem ser analisadas através de chaves analíticas propostas por autores como Albert Hirschman, Jefrey Alexander, Antony Giddens, Ülrich Beck, Nestor Garcia Canclini, Bente Halkier e Michele Michellet, entre outros, que não desmerecem a vida privada como espaço de luta pela emancipação.

O termo consumo político, ou politizado, tem sido utilizado, por diversos pesquisadores, para mostrar que o consumo é uma arena de tomada de decisão carregada de potenciais conflitos de valores e desejos, de capacidade política e de restrições socioeconômicas (CANCLINI, 1996; MICHELETTI, 2003; PORTILHO, 2005). Esta visão difere substancialmente das visões convencionais sobre o fenômeno do consumo, que tende a vê-lo ou como mera compra e aquisição de bens e serviços no mercado com base em decisões sobre preço e qualidade ou como gastos desmedidos e supérfluos (FOXALL, 2005; BARBOSA \& CAMPBELL, 2006).

Através de um processo de politização e ambientalização do consumo (PORTILHO, 2005 e 2006), o interesse pela esfera pública e a ação política passam a ser vividas também através de certas práticas de consumo, muitas vezes em detrimento das formas tradicionais de participação (partidos políticos, sindicatos, eleições, manifestações, movimentos sociais institucionalizados etc.). Temos, como consequiência, a construção de uma nova categoria - o "consumidor responsável" - que manifesta grande envolvimento com a questão ambiental, se auto-identifica como um ator social importante e se auto-atribui responsabilidades e deveres com relação à mesma (PORTILHO, 2008).

Assim, ao contrário das abordagens que analisam as propostas de "consumo responsável" como uma transferência de responsabilidades do Estado e do mercado para o consumidor individual ${ }^{12}$,

12 O problema com estas abordagens é que adotam uma postura teórica universalizante sobre o consumo, sem distinguir os múltiplos significados e usos sociais do mesmo entre os diferentes grupos sociais, além de negligenciarem a percepção dos agentes sociais sobre seus próprios atos (BARBOSA, 2004). Nestes casos, a crítica social e a posição moral do pesquisador parecem prevalecer sobre a pesquisa empírica e a análise da realidade concreta. 
outras abordagens buscam explicá-lo e compreendê-lo analisando, com base em dados empíricos, o processo de auto-atribuição de responsabilidades por parte dos consumidores que se engajam nesta prática (EDEN, 1999 ${ }^{13}$; PORTILHO, 2008).

Vivida como uma forma de ação política na esfera privada, a auto-atribuição de responsabilidades pode ser compreendida como consequiência de alguns fatores que têm transformado práticas locais e experiências sociais nas últimas quatro ou cinco décadas, como a globalização, a destradicionalização e a reflexividade social. GIDDENS (1996), por exemplo, ressalta que

nossas atividades cotidianas são cada vez mais influenciadas por eventos que acontecem do outro lado do mundo. De modo oposto, hábitos dos estilos de vida locais tornaram-se globalmente determinantes. Dessa forma, minha decisão de comprar um determinado artigo de vestuário tem implicações não só para a divisão internacional do trabalho, mas também para os ecossistemas terrestres (p.13).

Na ordem social considerada por Giddens (1996) como póstradicional, perderíamos as referências dadas pelas tradições e teríamos que decidir e escolher, por nós mesmos, "na condição de indivíduos e humanidade coletiva, o que é a natureza e como devemos organizar nossas vidas em relação a ela" (p.59). Com isso, os indivíduos precisam se acostumar a refletir e a filtrar as informações sobre todos os aspectos rotineiros da vida cotidiana, tomando decisões com base nessas reflexões e conhecimentos. Ao incorporar a reflexividade social, a auto-atribuição de responsabilidades poderia ser interpretada como uma importante forma de renovação da ação política contemporânea. $\mathrm{O}$ relativo crescimento

13 Em sua pesquisa, Eden (1993) examina a percepção dos indivíduos sobre suas responsabilidades e as possíveis tensões produzidas entre esta percepção e o comportamento propriamente dito. Conclui que a auto-atribuição de responsabilidades está ligada à percepção da eficácia da ação individual e à percepção sobre a possibilidade de algum controle que o indivíduo possa manter sobre o resultado de seu comportamento. Assim, onde pouco controle é percebido, o indivíduo teria pouca crença na eficácia do seu comportamento, porque seu esforço parece inútil; onde forte controle é percebido o indivíduo teria uma crença mais forte na eficácia de seu comportamento. Logo, a percepção da eficácia reforçaria a auto-atribuição de responsabilidade. 
da liberdade de escolha dos consumidores é conectado a uma busca pela emancipação, identidade pessoal e autonomia na esfera privada, apontando para novas formas de ação política.

A partir desses fenômenos, novas preocupações se juntariam às políticas emancipatórias tradicionais, dando origem ao que Giddens (1996) chama de políticas de vida, ou seja, aquelas que apontam para um padrão de engajamento relacionado às lutas sobre como queremos viver, como indivíduos e como humanidade, num mundo que era determinado pela tradição e pela natureza e que agora se encontra, cada vez mais, submetido às decisões humanas.

De forma semelhante, Beck (1997 e 2002) enfatiza que, em contraposição à descrença nas instituições políticas tradicionais (partidos, sindicatos, eleições, manifestações, movimentos sociais etc.), surge um renascimento não institucional do político, em que distintas áreas sociais passam a se constituir como uma nova cultura política. Assim, se o conceito de política significava, na modernidade clássica, deixar a esfera privada para dedicar-se à pública, vemos agora a invasão do político na esfera privada de forma que as experiências que eram consideradas declínio ou morte da política podem ser pensadas como reposicionamento do político. Nesse sentido, Beck observa, na modernização reflexiva, uma ampliação do conceito de política na medida em que a redução da participação pública nas esferas tradicionais reflete um processo de transição em que as velhas políticas dão lugar às novas políticas, que estariam concentradas na vida privada. Este renascimento não-institucional do político pode ser explicado por meio do conceito de subpolítica, uma política à margem e além das instituições políticas dos Estados-Nação; uma política direta que envolve a participação individual nas decisões.

Para Beck (1997), "na sociedade de risco global, a privacidade - como a menor unidade concebível do político - contém dentro de si a sociedade mundial" (p.61). Esta nova qualidade do político se fortalece justamente com a expansão da preocupação ecológica e com os riscos associados ao desenvolvimento tecnológico. Assim, para Beck (2002), o lugar do político na sociedade de risco global não é a rua, mas a televisão, a Internet e o mercado. 
A teoria neomoderna proposta por Alexander (1995) ajuda a compreender a transição no padrão de ação política nas sociedades contemporâneas - das ações radical-coletivistas, do período de antimodernização dos anos 60 e 70, para as ações românticoindividualistas, do período de neomodernização, a partir dos anos 90. Estas formas emergentes de ação política seriam mais realistas e pragmáticas por enfatizarem a ação de indivíduos reais e não de sujeitos históricos coletivos, como as categorias "nação", "classe social" ou "movimentos sociais". Isso se explicaria por um certo desgaste tanto das ações radicais-coletivistas quanto das teorias pós-modernas da fragmentação do indivíduo e do fim das grandes narrativas revolucionárias, predominantes na década de 80 . As narrativas e formas de ação política atuais - emancipatórias, individualistas e românticas, mas igualmente heróicas - parecem conectadas a uma ampla variedade de ações na esfera do mercado. Paralelamente, desenvolve-se uma narrativa mais emancipatória do mercado, na qual as idéias deste são apropriadas de forma coletivista, especialmente a partir da redefinição da Nova Sociologia Econômica e dos estudos das redes sociais.

Assim, a reconvergência neomoderna, abordada por Alexander (1995), enfatiza o (res)surgimento de uma narrativa emancipatória do mercado em que este passa a ser visto como uma relação social e interativa, que muito pouco se assemelha a um mercado capitalista explorador, na medida em que a narrativa heróica reaparece por meio de movimentos sociais com uma ampla variedade de motivações para construir novos direitos e formas de ação.

Canclini (1996) também considera as transformações nas formas de engajamento político, apontando para uma redução da participação, do interesse e da confiança nas instituições políticas tradicionais e, ao mesmo tempo, para uma reestruturação dos vínculos entre consumo e cidadania.

A aproximação entre a cidadania, a comunicação de massas e o consumo tem, entre outros fins, reconhecer estes novos cenários de constituição do público e mostrar que para viver em sociedades democráticas é indispensável reconhecer que o mercado de opiniões cidadãs inclui tanta variedade e dissonância como os mercados de roupa e entretenimento. 
Assim, para Canclini (1996, p. 196), "a expansão das comunicações e do consumo geram associações de consumidores e lutas sociais, ainda marginais, mas melhor informados sobre as condições nacionais e internacionais".

Os debates em torno do tema da cidadania têm apontado para uma ampliação do seu conceito, enfatizando um sentido inovador de uma "nova cidadania" que estende-se além dos limites espaciais, temporais e materiais (DAGNINO, 1994; CANCLINI, 1996; LISTER, 2007), libertando-o de sua exclusiva conexão com o Estado. Uma nova noção de cidadania incorpora elementos das sociedades contemporâneas, como o papel das subjetividades, a emergência de novos sujeitos sociais, a emergência de direitos sociais de novo tipo e a ampliação do espaço da política. Trata-se de um entendimento do conceito de cidadania e participação política não apenas ligado à estrutura formal da sociedade, como os direitos reconhecidos pelos aparelhos estatais para os que nasceram num mesmo território, mas também às práticas sociais e culturais que dão sentido de pertencimento e identidade social. Outro aspecto relevante é a visão historicizada da cidadania, destacando seu caráter de estratégia política, ou seja, aquele que expressa e responde a um conjunto de interesses, desejos e aspirações de uma parte significativa da sociedade (DAGNINO, 1994). Enquanto estratégia, o conteúdo da cidadania é sempre definido pelas diversas formas de luta política, sendo capaz, portanto, de incorporar novas dimensões da subjetividade, bem como novas aspirações, desejos e interesses, na medida em que esses consigam se generalizar como interesse coletivo e se instituir como direitos (DAGNINO, 1994).

Pesquisa desenvolvida por Halkier (1999) com jovens dinamarqueses e a forma como lidam com propostas e exigências por considerações ambientais no consumo ${ }^{14}$ aponta para um fato

14 A pesquisa mostra que os jovens dinamarqueses lidam com estas propostas e exigências de três maneiras: (a) alguns rejeitam a consideração ambiental e social nas escolhas de consumo, alegando que essas devem ser uma responsabilidade do Estado e de outros atores; (b) alguns negociam essas exigências com outras que fazem parte da sua experiência cotidiana, enquanto (c) outros as integram totalmente na vida diária. Estas diferentes reações relacionam-se às formas como as pessoas interpretam e conectam novos fenômenos à vida 
fundamental: os consumidores, mesmo se bem informados e conscientes de suas responsabilidades sociais e ambientais, têm que lidar diariamente com dilemas relacionados a qual seu papel no enfrentamento desses problemas, qual a efetividade de suas ações e, ainda, quem são os atores responsáveis por esses problemas. Além disso, têm que negociar estas propostas com outras igualmente presentes e em disputa na vida diária (consumption junction), como desejos, hábitos, tradições, preferências, gostos estéticos e restrições financeiras, entre outras.

A pesquisa de Halkier (1999) mostra, ainda, que as propostas de consumo sustentável podem ser interpretadas como uma forma de controle sobre a vida diária, caso as exigências por considerações ambientais sejam encaradas como uma moral absoluta. Isso pode significar uma racionalização da esfera íntima (obrigação de escolhas racionais na esfera íntima), conforme descrito por Giddens (1991), levando talvez a contra-reações de rejeição da responsabilidade ambiental, numa tentativa de contrariar esse aumento da racionalização. No entanto, pode significar também um aumento da autoridade do consumidor, a partir do momento em que este pode reapropriar conhecimentos e competências das práticas da vida diária em áreas onde o conhecimento e a competência leiga foram perdidos (GIDDENS, 1991; BECK, 1997).

Esse processo pode, ainda, contribuir para aumentar o sentimento de pertencimento na sociedade, uma vez que os consumidores podem perceber o significado de suas próprias ações em relação aos seus efeitos no meio ambiente e em outros grupos sociais, conectando as esferas local e global (GIDDENS, 1991). E isso poderia produzir sentimentos de cidadania mais fortes, uma vez que os consumidores passariam a ver suas próprias práticas como pertencendo a uma comunidade política mais ampla (HALKIER, 1999; CANCLINI, 1996).

$\mathrm{O}$ ato de selecionar e adquirir mercadorias, portanto, não pode ser compreendido como um ato individual e individualizante.

diária. A autora conclui que as reações variam se os consumidores conectam as propostas de consumo responsável a práticas, valores e significados já existentes em seus grupos e redes sociais. 
Ao contrário, o consumo se relaciona a duas formas de alteridade (MILLER, 2002): uma relação entre quem compra e para quem se compra, em geral a família; e uma relação cosmológica que transcende qualquer utilidade imediata, pois assume a forma "não de sujeito ou objeto, mas dos valores aos quais as pessoas desejariam se dedicar” (p.27). A seleção de mercadorias está, portanto, relacionada às relações sociais e aos valores mais importantes para a pessoa responsável por esta tarefa. No entanto, a idéia de responsabilidade pode ser ampliada para outros grupos sociais e para uma idéia abstrata de "mundo", "natureza" e "planeta" (PORTILHO, 2008).

Halkier (1999) lembra que o debate e a prática sobre um consumo menos ambientalmente danoso podem ser experimentados como tendo lugar numa comunidade, mas esta não deve ser compreendida, apenas, como associações físicas concretas, tais como movimentos e organizações que guiam os participantes na mesma direção. Assim, os consumidores que incorporam as considerações ambientais podem se sentir parte de uma comunidade imaginária difusa que ajuda a fazer com que suas práticas se tornem mais úteis e significativas em relação à melhoria do meio ambiente. Ao trocar experiências dentro de suas redes sociais podem reapropriar competências na vida diária e, portanto, fortalecer sua própria autoridade em relação às lógicas institucionais (GIDDENS, 1991). Halkier (1999) argumenta, ainda, que a política está presente em todas as relações e estruturas da sociedade onde a vida social é produzida e reproduzida. Trata-se de um conceito de política formado pelo poder em sua capacidade construtiva e transformadora (e não pelo poder como capacidade de controle) e de um modelo de democracia que se baseia no princípio da autonomia, ou seja, na idéia de que todo cidadão pode exercer uma influência relativamente autônoma nas suas condições de vida, inclusive na esfera íntima.

A ênfase nas ações via atividade de consumo na vida diária pode possibilitar ativar grupos de cidadãos que não têm recursos políticos ou que não desejam participar, via voz, na esfera pública, embora não deva substituir a participação política tradicional (CANCLINI, 1996). Assim, quando os consumidores lidam com dilemas diários relacionados a exigências por considerações ambientais no consumo, eles estão participando na formação de experiências relacionadas aos conflitos 
políticos sobre que atores e instituições devem ser responsáveis por diferentes problemas e soluções (HALKIER, 1999).

Em uma primeira aproximação, os consumidores politizados parecem reunir as seguintes características: (a) grande envolvimento com questões socioambientais; (b) se auto-atribuem responsabilidades e deveres com relação à melhoria do meio ambiente e da qualidade de vida; (c) não são, necessariamente, engajados em movimentos sociais institucionalizados; (d) preferem agir na esfera do consumo do que através de ações políticas convencionais (e) se auto-identificam como um ator social importante e, finalmente, (f) acreditam na importância e eficácia de suas ações.

\section{Conclusões}

A partir das reflexões aqui compartilhadas, vale ressaltar a necessidade de investigações empíricas que nos permitam problematizar e apontar as oportunidades e barreiras, os limites e possibilidades para a incorporação de novas formas de ação política na esfera individual, tal como a proposta de consumo responsável. Apesar de diversas proposições, cartilhas, relatórios e debates que propõem estratégias de solidariedade e de política ambiental centradas no consumo, a idéia de que os cidadãos deveriam modificar e/ou restringir seu consumo individual e doméstico em prol de melhorias sociais e ambientais não tem sido bem compreendida, além de ser palco de inúmeras controvérsias. Entre outras questões, sugere-se investigar: qual o papel dos consumidores (individuais ou organizados) na construção dos mercados? Quais os limites e possibilidade de ações como boicote e buycott? Como, de que forma e porque (ou porque não) os cidadãos individuais percebem suas responsabilidades e seus papéis? Quais as possibilidades de aumento da autonomia política na participação via consumo? Em que medida conjugam, ou não, a participação via consumo com formas institucionalizadas e coletivas de participação? Esperamos que esta reflexão sirva como estímulo a outros pesquisadores. 


\section{Referências}

ALEXANDER, J. Modern, ante, post, and neo: how intellectuals have coded, narreted, and explained the "crisis of our times". In: Jeffrey Alexander. Fin-de-siècle social theory: relativism, reduction, and the problem of reason. Londres: Verso, 1995.

ANDREWS, C. The circle of simplicity - return to the good life. New York: Harper Collins, 1997.

BARBOSA, L. Sociedade de consumo. Rio de Janeiro: Jorge Zahar, 2004.

BARBOSA, L. Apresentação. In: BARBOSA, L. \& CAMPBELL, C. Cultura, consumo e identidade. Rio de Janeiro: Editora FGV, 2006.

BARBOSA, L. \& CAMPBELL, C. O estudo do consumo nas ciências sociais contemporâneas. In: BARBOSA, L. \& CAMPBELL, C. Cultura, consumo e identidade. Rio de Janeiro: Editora FGV, 2006, pp. 21-44.

BAUDRILLARD, J. A sociedade de consumo. Rio de Janeiro: Elfos, 1995.

BLEE, K. Family patterns and the politicization of consumption. Sociological Spectrum. Vol. 5, № 4: 1985, pp.295-316.

BOURDIEU, P. A distinção: critica social do julgamento. Porto Alegre: Zouk, 2008.

BECK, U. A reinvenção da política: rumo a uma teoria da modernização reflexiva. In: GIDDENS, A. et alii. Modernização reflexiva: política, tradição e estética na ordem social moderna. São Paulo: Unesp, 1997.

. La sociedad del risco global. Madrid: Sieglo XXI, 2002.

CANCLINI, N. Consumidores e cidadãos: conflitos multiculturais da globalização. Rio de Janeiro: UFRJ, 1996.

DAGNINO, E. Os movimentos sociais e a emergência de uma nova noção de cidadania. In: DAGNINO, E. (org.). Anos 90: política e sociedade no Brasil. São Paulo: Brasiliense, 1994, pp.103-15.

DOUGLAS, M. \& ISHERWOOD, B. O mundo dos bens - para uma antropologia do consumo. Rio de Janeiro: Editora da UFRJ, 2006.

DOBSON, A. (org.). The green reader. London: Andre Deutsch, 1991. 
EDEN, S.E. Individual environmental responsability and its role in public environmentalism. Environmental and planning, v.25, 1993.

EDWARDS, T. Contradictions of consumption - concepts, practices and politics in consumer society. Buckingham: Open University Press, 2000.

ELGIN, D. Voluntary simplicity - toward a way of life that is outwardly simple, inwardly rich. New York: Willian Morrow: 1993.

FERRERAS, N. O cotidiano dos trabalhadores de Buenos Aires (1880-1920). Niterói: Eduff, 2006.

FOXALL, G. Understanding Consumer Choice. Basingstoke: Palgrave Macmillan, 2005.

FRANK, Dana. Purchasing power: consumer organizing, gender and the Seattle labor movement (1910-1929). Cambridge: Cambridge University Press: 1994.

. Food wins all struggles: Seattle labor and the politization of consumption. Radical History Review. № 51: 1991.

FREITAS, A. Aliança entre movimentos ambientalistas e de consumidores: o caso da "Campanha por um Brasil Livre de Transgênicos”. IV Encontro da ANPPAS. Brasília, 2008.

GENDRON, C.; BISAILLON V. \& OTERO, A. I. The institutionalization of Fair Trade: more than a degraded form of social action. Journal of Business Ethics. 2006.

GEUS, M. Ecological utopias: envisioning the sustainable society. Utrecht: International Books, 1999.

GIDDENS, A. As consequîencias da modernidade. São Paulo: UNESP, 1991.

. Para além da esquerda e da direita: o futuro da política radical. São Paulo: UNESP, 1996.

GREEN, K.; MORTON, B. \& NEW, St. Greening organizations. Organization \& environment. Vol. 13, no 2, june/2000.

HALKIER, B. Consequences of the politicization of consumption: the example of environmentally friendly consumption practices. Journal of Environmental Policy and Planning. 1:25-41: 1999. 
HARVEY, M. et ali. Between demand and consumption: a framework for research. Centre for Research on Innovation and Competition. Discussion Paper. №. 40. Manchester, University of Manchester, 2001.

ISIN, E. \& WOOD, P. Citizenship and identity. London: Sage, 1999.

KLEIN, N. Sem logo - a tirania das marcas em um planeta vendido. Rio de Janeiro: Record, 2002.

LASH, S. \& URRY, J. Economies of signs and space. London: Sage, 1994.

LINDEN, M. Working class consumer power. International Labor and Working-class History. № 46: 1994.

COHEN, L. The class experience of mass consumption - workers as consumers in interwar America. In: MILLER, D. (Ed.). Consumption: critical concepts in the social sciences. Vol. IV, London/New York, Routledge: 2001.

LISTER, R. Inclusive Citizenship: Realizing the Potential. Citizenship Studies. 11, 1:49-61, 2007.

McCORMICK, J. Rumo ao paraíso: a história do movimento ambientalista. Rio de Janeiro: Relume-Dumará, 1992.

MICHELETTI, M. Political virtue and shopping: individuals, consumerism, and collective action. New York: Palgrave, 2003.

MILLER, D. (Ed.). Acknowledging consumption: a review of new studies. Londres: Routledge, 1995.

. (Ed.). Consumption: critical concepts in the social sciences. Vol. IV. London/New York: Routledge, 2001.

. Teoria das compras. O que orienta as escolhas dos consumidores. São Paulo: Nobel, 2002.

NESTLE, M. Food Politics. Berkley/Los Angeles/London, University of California Press, 2002.

NUNES, E. A Revolta das Barcas - populismo, violência e conflito politico. Rio de Janeiro: Garamond, 2000.

PAAVOLA, J. Economics, ethics and green consumerism. In: COHEN, M. \& MURPHY, J. (Eds). Exploring sustainable consumption: 
environmental policy and the social sciences. Oxford: Elsevier Science, 2001, pp. 79-96.

PORTILHO, F. Sustentabilidade ambiental, consumo e cidadania. São Paulo: Cortez, 2005.

. Ambientalização do consumo: alianças entre movimentos ambientalistas e movimentos de defesa dos consumidores. Paper apresentado no GT1 do III Encontro Nacional da ANPPAS. Brasília, 2006.

. Consumidores de alimentos orgânicos: discursos, práticas e auto-atribuição de responsabilidade socioambiental. XXVI Reunião Brasileira de Antropologia. Porto Seguro, 2008.

PORTILHO, F. \& CASTAÑEDA, M. Certificação e confiança face-a-face na feira de produtos orgânicos. IV Encontro da ANPPAS. Brasília, 2008.

. Consumo e política: neo-modernismo e reflexividade social. Paper apresentado no GT4 do XIV Congresso Brasileiro de Sociologia. Rio de Janeiro, 2009.

RIOS, J.; LAZZARINI, M. \& NUNES Jr., V. (Orgs.). Código de defesa do consumidor comentado. Série Cidadania. São Paulo: IDEC/Globo, 2001.

SCHOR, Juliet B. The overspent american - why we want what we don't need. New York: Harper Perenial, 1998.

SCHWARTZ, S. H. Words, deeds and the perception of consequences and responsabilities in action situations. Journal of Personality and Social Psychology. N.19, 1998.

SODRÉ, M. A construção do direito do consumidor: um estudo sobre as origens das leis principiológicas de defesa do consumidor. São Paulo: Atlas, 2009.

STOLLE, D; HOOGHE, M. \& MICHELETTI, M. Politics in the supermarket: political consumerism as a form of political participation. International Political Science Review. Vol. 26 (3), 2005.

VERGARA, S. Impacto dos direitos dos consumidores nas práticas empresariais. Rio de Janeiro: FGV, 2003.

WILKINSON, J. Sociologia econômica, a teoria das convenções e o funcionamento dos mercados: "inputs" para analisar os micro e 
pequenos empreendimentos agroindustriais no Brasil. Ensaios FEE [Online] 23:2, 2002. Disponível: http://revistas.fee.tche.br/index.php/ ensaios/article/view/2042/2424.

. Fair trade: dynamic and dilemmas of a market oriented global social movement. Journal of Consumer Policy. Special Issue. Volume 30, Number 3, September, 2007.

. Mercados, redes e valores. Porto Alegre: UFRGS, 2008.

WOORTMANN, K. Hábitos e ideologias alimentares em grupos sociais de baixa renda. Relatório Final de Pesquisa. Série Antropologia 20. Brasília, UnB, 1978. (Disponível em http://www.unb.br/ics/dan/ Serie20empdf.pdf - acessado em janeiro/2008).

ZAVESTOSKI, St. Environmental concern and anti-consumerism in the self-concept: do they share the same basis? In: COHEN, M. \& MURPHY, J. (eds.). Exploring sustainable consumption: environmental policy and the social sciences. Oxford: Elsevier Science, 2001.

\section{Abstract \\ New market actors: economic social movements and politicized consumers}

This article presents reflections on new market actors, and economic social movements in particular - that is, those in which actors build a new culture of political action that seeks to reappropriate the economy through their own values. Some examples of this are the movements organized around "solidarity economics", fair trade, geographic indications, "slow food" and consumer organization. This interface of social movements and the market may be the most marked, differentiated and polemic trait of contemporary political mobilizations. Nonetheless, beyond economic social movements, this article simultaneously emphasizes and problematizes political action within the sphere of individual consumption, that is, that which has been referred to as "political consumption".

Keywords: economic social movements, consumer movements, political consumption. 